\title{
As muitas fronteiras do Cerro do Jarau
}

\author{
The many borders of the Jarau Hill \\ Las muchas fronteras del Cerro del Jarau
}

Cesar Augusto Barcellos Guazzelli*

\section{Resumo}

Este artigo propõe o estudo de três diferentes tipos de fronteira, mas que podem confluir numa única direção: 1) uma espacial, aparentemente aquela que é identificável e material, mas que necessita da mediação de uma construção histórica; 2) outra textual, que diz respeito aos desenvolvimentos teóricos que dão conta tanto do tema quanto da produção ficcional que tem como objeto esses territórios e suas gentes; 3) finalmente, aquela dimensão entre o verossímil e o fantástico, que muitas vezes é capaz de revelar aspectos dificilmente conhecidos empiricamente.

Palavras-chave: Ficção. Fronteiras. História e literatura. Limites espaciais. Rio da Prata.

\section{Rastreando o cerro}

Antes que nada, algumas considerações sobre o tema deste artigo. As fronteiras quase sempre se constituíram no meu objeto principal de investigação. Nesse sentido, organizei, em 2008, o grupo de pesquisa Fronteiras Americanas, do qual derivou o Grupo de Trabalho (GT) da Associação Nacional de História - Seção Rio Grande do Sul (ANPUH-RS). ${ }^{2}$ No mesmo ano, coordenei o projeto Regiões e Nações na História e na Literatura do Rio da Prata nos Oitocentos: fronteiras espaciais, comportamentais e textuais, aprovado em Edital Universal do Conselho Conselho Nacional de Desenvolvimento Científico e Tecnológico (CNPq), encerrado em 2011. Entre 2011-2012, realizei

\footnotetext{
Professor titular do Departamento de História, do Programa de Pós-Graduação em História e do Mestrado Profissional de História da Universidade Federal do Rio Grande do Sul (Ufrgs).
}

Recebido em: 04/01/2018 - Aprovado em: 24/01/2018 http://dx.doi.org/10.5335/hdtv.18n.2.8073 
estágio pós-doutoral na Universidad $\mathrm{Na}$ cional de General Sarmiento, Buenos Aires, com apoio da Coordenação de Aperfeiçoamento de Pessoal de Nível Superior (Capes), para desenvolver a pesquisa "A invenção da barbárie: uma aproximação histórico-literária da violência no espaço platino do Século Dezenove". Desde então tenho me ocupado mais com as questões fronteiriças relacionadas também à literatura, em especial, à gauchesca platina e rio-grandense, por sua originalidade e seu papel na criação de significados regionais e nacionais. ${ }^{3}$

Por isso tudo, João Simões Lopes Neto, o Cerro do Jarau e sua salamanca! E neles múltiplas fronteiras: nas origens espaciais e textuais, na definição dos limites da literatura, nos espaços fronteiriços, na literatura gauchesca e na obra simoniana. Para dar conta desses aspectos, divido o texto em partes, buscando como a literatura fantástica gauchesca pode revelar alguns comportamentos fronteiriços em fronteiras territoriais. O objeto/fonte deste artigo é "A Salamanca do Jarau", narrativa do escritor João Simões Lopes Neto, publicada no livro Lendas do Sul. Existem várias edições da obra (ANTUNES, 2003, p. 50-56). ${ }^{4}$ Uso a publicação da IEL/Unisinos (LOPES NETO, 2006), que destina um tomo para Contos Gauchescos e outro para Lendas do Sul, tendo recebido ambos um tratamento muito cuidadoso do escritor Aldyr Garcia Schlee, responsável pela introdução, pela descrição de variantes, pelas notas e pelo glossário; mais volumosa, esta edição permitiu que houvesse cotejo com as anteriores (ANTUNES, 2003, p. 96-97).

\section{Pedras que despencam de céu e fronteiras que se criam}

O Cerro do Jarau é um mistério da natureza desde muito antes daqueles sobrenaturais que encerra. Numa área pampiana da Campanha rio-grandense, atual município de Quaraí, ergue-se naquele "mar verde" um semicírculo de 14 quilômetros de diâmetro que sobe até aproximadamente 200 metros, limitado ao sul pelo rio Quaraí e seu afluente, o arroio Quaraí-Mirim, e ao norte pelo arroio Garupá, também tributário daquele rio. O cerro está muito próximo do atual limite entre Brasil e Uruguai, que é o próprio rio Quaraí. Pesquisas geológicas recentes indicam que o cerro é formado pelas bordas de uma cratera, causada pelo impacto de um meteoro de grandes dimensões que teria ocorrido há aproximadamente 130 milhões de anos antes do presente (AP) (CRÓSTA, 2007, p. 173). Tais fenômenos são raros, e apenas seis estruturas resultantes do choque de grandes bólidos como o que originou o Cerro do Jarau existem no Brasil. Apesar de ainda serem discutidas outras hipóteses, as conclusões de que o cerro seja um "astroproblema" têm sido apresentadas em importantes revistas nacionais (PHILIPP, 2010) e internacionais (CROSTA, 2007). A furna aparece nas descrições externas do cerro, nas não encontrei nenhum relato espeleológico sobre seu interior misterioso.

Estas características físicas não são suficientes para compreender o Jarau. O cerro está numa zona de fronteira, que é marcante para os horizontes da província do Rio Grande. Saliento que o Brasil faz fronteira com nove países, numa extensão de quase 17 
mil quilômetros, e são onze os estados que têm fronteiras internacionais. No Rio Grande do Sul, a fronteira mede 3.307 quilômetros, pouco mais da metade de seus limites: 1.003 com a Argentina e 724 com o Uruguai. $\mathrm{O}$ estado estremenho tem sua história ligada às fronteiras platinas e fez delas parte de uma identidade regional muito forte. Se a fronteira é um espaço, é necessário pensar na formação deste espaço; se é o fronteiriço quem o constrói, mais necessário que tratar das relações entre os homens e a natureza, é investigar aquelas dos homens entre si no processo de apropriação e exploração das paisagens. Nesse sentido, é mister uma avaliação crítica da produção historiográfica sobre as fronteiras meridionais.

A primeira delas é aquela que equipara fronteira com limite político. Aceita como historiografia oficial, atribui aos rio-grandenses uma incontestável adesão ao Brasil, sendo o patriotismo comprovado pelos "serviços" prestados pelos homens do passado na garantia das fronteiras contra os "castelhanos". Esses estudiosos estabeleceram equivalência entre fronteira e limites nacionais, e, a partir daí, as diferenças entre fronteiriços dos dois lados: o gaúcho rio-grandense, sério e ordeiro, diferente do gaucho platino, associado à bandidagem e ao caudilhismo. $^{5}$

Tais concepções da fronteira foram problematizadas a partir dos anos 1970, aparecendo, em contrapartida noções, que a tratavam como espaço "aberto", resultante de processos históricos de ocupação/formação da propriedade privada, que não podia ser enquadrado nos limites políticos. A semelhança na apropriação dos bens de produção
- gados, terras e escravos - de um e de outro lado da fronteira configurou relações sociais horizontais e verticais mais parecidas entre estas áreas fronteiriças, distantes dos respectivos governos centrais, do que em relação às unidades voltadas às atividades exportadoras e fiadoras das organizações nacionais. Os processos socioeconômicos que produziram as "fronteiras" não se confundiam com os "limites", determinados por ações jurídico-políticas, que existiriam apenas nos mapas oficiais.

A partir de meados da década de 1990, alguns historiadores realizaram suas pesquisas pensando na estremadura inserida no espaço platino, sem deixar de ser parte da América portuguesa, primeiro, e do Império do Brasil, mais tarde. Os fronteiriços eram atores sociais que respondiam às tensões geradas pelas relações locais, assim como aquelas dos Estados envolvidos. Isso se refletiu numa produção historiográfica significativa, que adentra nos primeiros anos do novo milênio. $\mathrm{O}$ corolário destas reflexões foi a concepção original de Mariana Thompson Flores de uma fronteira que é "manejável" pelos agentes sociais deste espaço que podem circular em ambos os lados da "linha", na medida em que são conhecidos os códigos vigentes em cada um deles. Assim, os homens da fronteira têm outras possibilidades de sobrevivência e novas modalidades de poder. Importa saber que a fronteira não é "aberta", e que, justamente, o reconhecimento de sua existência é o que possibilita o seu "manejo". Ou seja, usar estratégias adequadas para um e outro lado do limite político torna a fronteira um "recurso" para as gentes que ali vivem (THOMPSON FLORES, 2016, p. 47-82). 
Essas considerações permitem que os temas fronteiriços sejam privilegiados nos recortes cronológicos e temáticos mais variados. Nesse sentido, a historiografia produzida pelos pesquisadores do extremo sul se "apropriou" da fronteira como forma de criar um espaço próprio, também ele "fronteiriço", porque não pode ser submetido aos limites de uma história "nacional" ou mesmo "provincial". Pela fronteira, circulam ideias políticas, literárias e também lendárias. Como as "salamancas"!

\section{Furnas que se abrem, diabos que aparecem, feiticeiras que se escondem.}

Qual é o significado que uma formação tão peculiar pode ter causado naqueles que primeiro chegaram ao Jarau? A misteriosa furna do cerro era uma singularidade nesta estrutura, muito escura e de uma enorme e desconhecida profundidade, associada ao desaparecimento de atrevidos que penetraram seu interior. Esteve decerto associada a crenças indígenas; no entanto, são as tradições de origem europeia que conformaram uma extensa mitologia sobre a covas e que lhe deram o nome de salamancas pela sua presumível origem em tempos medievais de Salamanca, na Espanha. Entre tantas, a Salamanca do Jarau!

O início das lendas está ligado à Cueva da Salamanca, uma furna misteriosa que seria uma das moradas do próprio diabo. Nos primeiros anos do século XV, o Marquês Enrique de Villena, astrólogo e nigromante, acompanhado de seis outros estudiosos das artes ocultas, teria sido um dos alunos de Satã neste lugar (MARCOS CELESTINO,
2004, p. 165). O relato mais denso e detalhado sobre a presença de diabos na cueva foi escrito pelo português Francisco Botelho de Moraes Vasconcelos, que se referiu à presença na furna de uma "diaba" chamada Mariálvara, uma figura de mulher, mas com pés de cabra (VASCONCELOS, 1733, p. 57). Mulheres no lugar do Demônio!

Tais temores já não faziam sentido, visto que, em vez de furna misteriosa, a cueva era apenas a sacristia da Igreja de São Cipriano que, por ser subterrânea, era acessada somente por uma estreita escada, o que lhe dava um ar de mistério (MARCOS CELESTINO, 2004, p. 163-164). Muito antes do tratado tão temeroso de Vasconcelos, a lenda inspirara obras cômicas de escritores espanhóis: o próprio Miguel de Cervantes Saavedra publicou, em 1615, um entremés ${ }^{6}$ sobre a Cueva de Salamanca, salientado o caráter simplório das crenças naqueles encontros com o diabo (CERVANTES SAAVEDRA, 1615). Em 1628, Juan Ruiz de Alarcón y Mendoz escreveu também uma comédia, La Cueva de Salamanca, em que os encantamentos mágicos se misturam ao cotidiano mundano, tratados como crendices populares (ALARCÓN Y MENDOZ, 1990).

Já a escritora pelotense Hilda Simões Lopes propôs uma interpretação original, deslocando a questão de Salamanca para Granada. A autora escreveu sobre uma parecença entre a história do gaúcho que entra na Salamanca do Jarau com personagens da "Lenda do soldado encantado", recolhida por Washington Irving em suas pesquisas na Alhambra, o palácio dos reis mouros de Granada (LOPES, 2003). ${ }^{7}$ Esta é a única versão das que li que atribui uma possível 
origem árabe à lenda, corroborando aquela contada por João Simões Lopes Neto.

Mas foi na América que a lenda de Salamanca prosperou, adquirindo contornos próprios. Essa disseminação se faz muito presente em narrativas populares da Argentina. A historiadora e folclorista Berta Elena Vidal de Battini recolheu histórias sobre a Cueva de Salamanca, e as versões que ouviu em suas pesquisas pelo país, num total de 38 casos, vieram de quase todas as províncias; elas se referem a encontros com diabos e bruxas por salamanqueros, ambiciosos que procuram pactos que os beneficiem com poderes sobrenaturais (VIDAL DE BATTINI, 1984, p. 331). No século XIX, já havia interessados nas crenças populares. Um deles, o poeta Rafael Obligado, lançou em 1877 o livro Santos Vega y otras leyendas argentinas, entre elas "La Salamanca", contando de um aventureiro que procura numa furna o Diabo, acompanhado de suas bruxas (OBLIGADO, 1969). O mesmo livro trata ainda de Santos Vega, um campeiro que se tornou lendário como o payador invencível que enfrentou o próprio diabo e ganhou dele.

No Uruguai, o escritor e antropólogo Daniel Granada fez um relato da lenda da Salamanca que alguns autores creem ser inspirador do texto de Simões Lopes (GRANADA, 1959). Naquele país há uma outra versão da Salamanca, de feitio muito diverso das que foram. As crenças se ligam ao Cerro Arequita, uma estrutura rochosa de 300 metros de alto e com antiguidade calculada em 130 milhões de anos AP, situada na área pampiana do departamento de Lavalleja. Parecido com o Jarau, o cerro tem grandes furnas, e numa delas se abrigaram três feiti- ceiras charruas, recebendo visitas daqueles que solicitavam soluções mágicas. Relatam-se casos de homens brancos cruéis com os indígenas serem castigados por trabalhos dessas feiticeiras. Diferentemente das outras versões, a palavra Salamanca não derivaria da cidade homônima, mas seria corruptela do termo indígena "slamanac", que significa ritual secreto (ABELLA, 2001). De toda sorte, é provável que, nos vizinhos platinos, estejam as origens da Salamanca do Jarau. Na versão contada por Simões Lopes Neto, a história andou pela redução jesuítica de Santo Tomé Apóstolo, e naqueles tempos o Jarau estava em terras de Espanha.

\section{Fatos que realmente aconteceram?}

Usar a literatura como fonte requer que determinadas considerações sejam feitas. Afinal, "os juízos de valor que a constituem são historicamente variáveis", ou seja, eles também têm "uma estreita relação com as ideologias sociais" (EAGLETON, 2006, p. 24). Parte-se do princípio de que qualquer reflexão a respeito da literatura enquanto testemunho histórico deve assumir um pressuposto materialista de análise, ou seja, de que a literatura não é transcendente historicamente. A análise de textos literários por uma perspectiva histórica deve considerar as circunstâncias em que tais textos não somente são produzidos, mas também são apreendidos pelos diversos grupos (CHARTIER, 2002). Chartier, portanto, propõe uma leitura histórica da obra literária, embasada nos fatos que construíram a obra, ou seja, texto e contexto. 
A Literatura, diferentemente da História, não está preocupada em dar conta cientificamente do passado. No entanto, "La recomposición del pasado que opera la literatura es casi siempre falaz juzgada en términos de objetividad histórica. La verdad literaria es una y otra la verdad histórica. Pero - aunque esté repleta de mentiras - o, más bien, por ello mismo - la literatura cuenta la historia que la historia que escriben los historiadores no sabe o no puede contar" (VARGAS LLOSA, 2002, 11). ${ }^{8}$ Os relatos literários devem ser apenas "verossímeis". Um tipo de literatura, no entanto, procurou uma veracidade que, se não substituía a História, tinha muito apelo: o romance histórico, de grande difusão no século XIX, protagonista de uma ideologia marcante, o nacionalismo; refletir sobre este papel da Literatura de uma ideologia talvez possa trazer algumas luzes acerca da questão inicial, proposta para este texto.

A respeito da formação da ideia de nação, partimos da concepção proposta por Benedict Anderson, que considera a nacionalidade, o nacionalismo e a nation-ness como artefatos culturais peculiares, cuja compreensão requer que se considere como esses artefatos se tornaram entidades históricas e de que modo seus significados variam no tempo. $\mathrm{O}$ autor sustenta a ideia de que o nacionalismo inventa nações onde elas não existem. Assim sendo, a Literatura penetra a realidade, criando, nos Estados nacionais, a segurança de uma comunhão anônima entre todas as pessoas, uma garantia para as nações (ANDERSON, 1989, p. 44). Nesse processo, o período literário denominado Romantismo teve uma grande importância na recriação de linguagens e de literaturas; na criação dessas identidades, era fundamental a "invenção" de passados que as legitimassem, e aqui o papel dos romances. Memória e identidade, eis o amálgama para a construção das nações!

O criador do romance histórico foi o escocês Walter Scott, que "inventou" um passado para seu país, primeiro, e para a Inglaterra, depois. Mas seu livro mais famoso é Ivanhoé (SCOTT, 1947), escrito em 1819, sobre a Inglaterra dos saxões conquistada pelos normandos. Na trama envolvendo os saxões contra a dominação dos normandos, forja-se ao final uma unidade inglesa, em torno do soberano normando Ricardo, o Coração de Leão, que retornava de uma cruzada com legitimidade para obter a aceitação das duas etnias. Não faltam, no romance, personagens de conduta fronteiriça, como o lendário Robin Hood, o bom ladrão, Tuck, um frade combatente, e Isaac, o mercador judeu.

Scott durante seu exílio em Londres, em 1831. Ele tornou-se um misto de romancista e historiador, com uma profícua obra, em que sempre procurou evidenciar o passado glorioso de Portugal, destacando o caráter guerreiro, belicoso, indomável e até cruel dos lusitanos d'antanho. Lendas e Narrativas (HERCULANO, 1992) talvez seja a obra mais coerente da sua literatura; as histórias contadas vão da conquista árabe da Península Ibérica até tempos posteriores à independência lusitana de Castela: "A Batalha do Crissus", que narra a vitória dos mouros sobre os visigodos; "O Alcaide de Santarém", que apresenta as intrigas no Califado de Córdoba e o papel dos reinos cristãos; "O Bispo Negro", "O Castelo de Farias" e "A Morte do Lidador", que relatam a 
separação de Portugal no século XII; e "Arras por Foro de Espanha", em que se reitera a autonomia conquistada.

Na América, onde o processo de organização nacional é mais recente, a construção de um passado que inventasse uma identidade contraposta às origens coloniais dos países europeus contra quem se lutava exigiu esforços mais intensos. Nesse sentido, encontramos uma diferença fundamental na criação de identidades: o caso norte-americano, que faz a apologia do pioneiro em relação aos ingleses; e o sul-americano, especialmente dos países do Rio da Prata, que barbariza os seus habitantes. Em ambos, o homem americano é fruto de uma fronteira e de uma miscigenação cultural, que foram mostradas primeiramente pela Literatura.

A versão americana do romance histórico foi criada por James Fenimore Cooper, que seria o "pai fundador" incontestável da literatura dos Estados Unidos, divulgando precocemente o país no mundo das letras internacionais. Suas obras mais famosas são os cinco romances que compõe a série The Leatherstocking Tales, protagonizados por um pioneiro da fronteira que se movia incessantemente para oeste a partir da formação dos Estados Unidos da América. O leatherstocking 9 era Nathaniel Bumppo, um caçador branco criado por índios moicanos, em diferentes fases de sua vida. ${ }^{10} \mathrm{O}$ escritor cria um modelo de "americano" distinto do europeu "civilizado" de hábitos refinados, ressaltando a fronteira espacial e cultural como formadora do espírito da nação. Esse paradigma deixou de lado a Europa e o Antigo Regime, assumindo os valores de América e da Revolução Americana (FREITAS, 2008, p. 44-49).
Na literatura da América Platina, não apareceu o pioneiro como protagonista das nações que se propunham. Ao contrário, na fronteira havia homens "sem Deus, sem Rei e sem Lei", que vieram a ser chamados de gaúchos, ou gauchos, em castelhano. Essa palavra é uma das tantas de origem ainda obscura, que recebeu muitos significados. Aparecida em fins do século XVIII, designava os hombres sueltos das campanhas platinas, tendo caráter pejorativo e uma rica sinonímia: vagamundo, gaudério, vago, malentretenido, cuatrero, entre tantas; todas elas se referiam a indivíduos que, por não terem relações de trabalho estáveis, viviam dos mais variados expedientes, quase todos associados a algum tipo de delito pelas autoridades.

Essa "barbárie" foi apontada pelos intelectuais do século XIX como um grande mal a extirpar em nome de uma "civilização". Esta dicotomia foi o argumento de Domingo Faustino Sarmiento em seu Facundo, livro canônico escrito em 1845 (SARMIENTO, 1996). Para ele, era o cotidiano das estâncias que originava a "barbárie": habituados à matança dos animais, passando pelas disputas em duelos à arma branca, os gauchos eram facilmente arrastados pelos seus chefes para as guerras civis, porque nelas defendiam um modo de vida que era incompatível com a "civilização" que a Europa trazia para as cidades. A Revolução de Independência originou o protagonismo destas hordas militares, que vinham do mundo rural assolar as cidades e impedir o progresso. Na América Latina, somava-se ainda isso a mistura racial, envolvendo etnias africanas e indígenas com povos ibéricos, que eram europeus em decadência. Uma expressão lite- 
rária candente da ojeriza aos gaúchos e seus caudilhos é El Matadero, escrito por Estebán Echeverría em 1838, considerado o primeiro conto argentino, assim como o primeiro texto realista do país (ECHEVERRÍA, 1999).

A contrapartida desta literatura produzida pelos intelectuais dos grandes centros latino-americanos, "europeizados" e em busca de projetos civilizatórios para os "males" do continente, foi uma produção textual muito original, que buscava nos campeiros a legitimação das "raízes nacionais". Esta era a chamada "gauchesca"!

\section{¡Ya se fueron los gauchos! E homens da cidade recriaram seusjeitos e falas.}

O gaucho d'antanho era um marginal. Forçado à ponta da baioneta pelos milicos, tornou-se peão de estância, soldado de linha, e terminou despilchado e a pé nos "corredores" e nas periferias das cidades. Foram os escritores platinos que se voltaram a eles; essa literatura é, portanto, "gauchesca" e não "gaúcha". Três temas são recorrentes: o passado idealizado, em que os gaúchos viviam harmoniosamente nos pagos dos quais foram expulsos; os gaúchos guerreiros, com os ideais americanos de liberdade e igualdade pela independência e contra os exércitos dos Estados centralizadores; e a sabedoria pampiana, aprendida com a experiência, mais confiável que a ciência ensinada nas escolas, que é talvez o tema mais presente nas diversas versões literárias dos gaúchos (GUAZZELLI, 2002, p. 109-110).

A primeira expressão da literatura gauchesca foi o oriental Bartolomé Hidal- go, engajado precocemente nas hostes de Artigas que acossaram os realistas espanhóis cercados em Montevidéu. Usando linguagem e formas poéticas populares, Hidalgo recontava os feitos artiguistas, portadores dos ideais libertários americanos contra a intolerável dominação do mundo colonial, herdada pelos organizadores dos Estados nacionais. Esta participação dos gauchos fazia da guerra uma extensão das suas vidas nas estâncias. Outra modalidade poética introduzida por Hidalgo foi o diálogo patriótico, uma forma pedagógica de, na linguagem campeira, dar entendimento à movediça cena política que se desenvolvia no Prata (HIDALGO, 1967).

Muitos cielitos e diálogos patrióticos de autores anônimos, produzidos durante as guerras civis na Confederação Argentina do século XIX, foram recolhidos por Eduardo Jorge Bosco, Francisco Acuña de Figueroa, Martiniano Leguizamón, Ricardo Rodríguez Molas. Essa produção homenageava os principais chefes caudilhos provincianos que lutavam contra os projetos de Estado centralizado, como Dorrego, Rosas, Quiroga, Peñaloza, Varela, entre muitos. Esse conjunto difuso e amplo chama-se comumente de Cancionero Federal (VIGNOLO, 1976). Mas também apareceu uma literatura gauchesca que fazia contraponto a essa massiva produção que se identificava com os ideais federalistas, e o já citado Hilario Ascasubi é o melhor exemplo deles, especialmente no cuidado com a reprodução do linguajar campeiro (ASCASUBI, 1998). 
Mas certamente o nome principal de toda a gauchesca foi José Hernández (2009) e seu canônico Martín Fierro, feito em duas partes. Em El Gaucho Martin Fierro, publicado em 1872, ele faz o resgate do gaucho malo de sua condição de "barbárie" atribuída pelos intelectuais urbanos e liberais. A transição para os "novos tempos" é essencial em Hernández para toda a dramaticidade da saga de Martín Fierro. De uma vida idílica como campeiro, foi remetido à força para o serviço militar; depois de anos de agrura, voltou ao lugar e não encontrou o rancho e a família. Por vingança tornou-se um gaucho malo, perseguido pela polícia, e terminou se refugiando entre os indígenas (HERNÁNDEZ, 2009, p. 7-87). Hernández, idealizando um passado anterior à subjugação do gaúcho, fez o primeiro libelo em defesa daqueles tipos que eram quase sempre associados ao delito (HALPERÍN DONGHI, 1985, p. 293).

Em 1879, Hernández publica uma continuação da saga, La vuelta de Martín Fierro. Num poema bem mais extenso, ele trata da volta ao mundo dos brancos, relegando a "barbárie" aos indígenas. Defendendo mulheres cativas, encontrando e ouvindo os sofrimentos dos filhos, ou na belíssima payada com o Moreno, Fierro faz as pazes com a "civilização" e se torna um "pai que dá conselhos". A sabedoria adquirida ao longo da existência é celebrada pelo autor (HERNÁNDEZ, 2009, p. 90-270).

Gaúchos como protagonistas da nação americana também aparecem na gauchesca uruguaia. É canônico o poema Los tres gauchos orientales, de Antonio Lusich, um "coloquio entre los paisanos Julián Giménez, Mauricio Baliente y José Centurión" (LUSICH, 1937, p. 23), no qual os três que lutaram junto aos blancos de Timoteo Aparicio conversam sobre a Revolución de las Lanzas que recém terminara (LUSICH, 1937). Também Javier de Viana buscou inspiração para seus cuentos na participação dos gauchos nas guerras civis; seus personagens costumam ser veteranos da gesta de Artigas, que se dispõem a mais uma lida pela pátria que ajudaram a construir, mesmo que isso implique sacrifício de seus bens e situações pessoais (VIANA, 2006).

\section{Simões Lopes Neto e o fantástico na fronteira do Jarau}

Na literatura gauchesca do Rio Grande do Sul, a ideia de pátria exibe as contradições ainda presentes: os rio-grandenses que deram seu sangue para afirmar a "marca portuguesa" no espaço platino castelhano foram os mesmos que se rebelaram e repeliram a autoridade do Império, e os chefes farroupilhas receberam por parte dos literatos o papel de liderança incontestável dos homens da campanha. Assim como nos países vizinhos, o termo "gaúcho" mudou paulatinamente de significado: de sinônimo de desocupado, ou mesmo de delinquente, aos poucos foi incorporando as melhores características dos trabalhadores campeiros e recebendo as loas de identidade da província sulina.

A literatura gauchesca teve, desde o final do século XIX, a preocupação em re- 
tomar para o Rio Grande do Sul seu protagonismo enquanto defensora dos interesses luso-brasileiros, de modo que o "gaúcho" rio-grandense tinha atitudes e modos distintos dos gaúchos "castelhanos". A par de servir de exemplo de campeiro que enfrenta as adversidades inerentes às lides pastoris, em condições ambientais também muito duras, os "gaúchos" tinham sido as verdadeiras "sentinelas" do Brasil, obstáculos intransponíveis às ambições platinas. Assim como essas interpretações eram arbitrárias, na medida em que "fronteiras" não se restringem a limites políticos, culturalmente houve "contrabando" de ideias oriundas do Rio da Prata, e a gauchesca rio-grandense guardou semelhanças com os textos literários argentinos e uruguaios.

Trato neste artigo do texto de um dos mais destacados entre os escritores gauchescos rio-grandenses, João Simões Lopes Neto: "A Salamanca do Jarau", publicada no volume Lendas do Sul, de 1913. Modernamente, essa publicação tem sido editada em conjunto com Contos Gauchescos, publicação do ano anterior.

No início de Contos Gauchescos, o autor anuncia o personagem-narrador: "Blau, o vaqueano", velho gaúcho que tinha sido um "furriel farroupilha" e se mantinha "desempenado arcabouço de oitenta e oito anos, todos os dentes, vista aguda e ouvido fino", compondo o "genuíno tipo - crioulo - rio-grandense (hoje tão modificado)" (LOPES NETO, 2006, p. 42). Noutro texto (GUAZZELLI, 2012), procurei mostrar como o escritor apresentava aspectos históricos de três momentos de guerra no "ciclo de vida" de Blau, também em distintas conjunturas do processo de formação dos Estados nacionais. Em "O anjo da vitória" (LOPES NETO, 2006, p. 127-132), Blau ainda menino de dez anos participa da Batalha do Passo do Rosário, em 20 de fevereiro de 1827, na Guerra da Cisplatina. Já "O duelo dos farrapos" (LOPES NETO, 2006, p. 147-153) se passa no início de 1844, tendo como clímax o duelo de morte entre Bento Gonçalves, Presidente da República Rio-Grandense, e Onofre Pires. Em "Chasque do imperador" (LOPES NETO, p. 93-99), o veterano cabo Blau foi ordenança de Pedro II em 1865 no cerco de Uruguaiana, início da Guerra do Paraguai.

Se os contos tratam de um tempo histórico em que viveu Blau, as lendas remetem ao passado colonial mais remoto, até mitos de criação, como em "A Mboitatá" (LOPES NETO, 2006, p. 187-193), a cobra de fogo que assola os campos por onde anda. Noutro artigo (GUAZZELLI, 2014), discuti como o autor, em três das Lendas do Sul, teve como objeto os marginalizados do mundo branco e masculino que comumente se mostra na gauchesca rio-grandense: "O lunar de Sepé" (LOPES NETO, 2006, p. 225-231), ${ }^{11}$ poema sobre o cacique guarani que enfrentou portugueses e espanhóis na defesa dos indígenas missioneiros; "O Negrinho do Pastoreio" (LOPES NETO, 2006, p. 235-242), menino negro torturado e morto pelo seu senhor; e "A Salamanca do Jarau" (LOPES NETO, 2006, p. 195-223), em que uma mulher pecadora assume o protagonismo da narrativa. As fronteiras do Rio Grande desbordam o espaço, também de conduta, da palavra contada e do fantástico.

Assim, chegamos ao Cerro do Jarau, fronteira entre países, "manejada" pelos 
fronteiriços de ambos, disputando ou partilhando terras e semoventes, por onde circula a política e a cultura. Não poderia faltar a Salamanca!

Antes da lenda de Simões Lopes, outra lenda sobre a Salamanca do Jarau. Segundo contemporâneos, ela teria sido visitada pelo tão discutido Bento Manoel Ribeiro, combatente já experimentado na Farroupilha, tendo ficado duas vezes ao lado dos rebeldes e outras duas, dos imperiais. Foi um dos seis generais dos farroupilhas e brigadeiro entre os caramurus. Se isso não recomenda seu caráter, indica que era um militar destacado. Seria invencível por ter obtido na salamanca o feitiço de corpo fechado e a Lança de Ébano, que tinha poderes mágicos (CARNEIRO, 2009, p. 13). ${ }^{12}$

"A Salamanca do Jarau" é o texto mais bem-acabado de Simões Lopes Neto, podendo ser considerado uma obra-prima da literatura nacional. A história tem um formato bastante encontradiço: um homem pobre, mas valente, enfrenta os perigos e feitiços de uma fada/bruxa encantada, que o premiaria se enfrentasse e vencesse criaturas criadas pelos feitiços dela. A temida e desejada Teiniaguá! A descrição do homem na primeira frase é definidora: "Era um dia... um dia, um gaúcho pobre, Blau, de nome, guasca de bom porte, mas que só tinha de seu um cavalo gordo, o facão afiado e as estradas reais" (LOPES NETO, 2006, p. 195).

Uma questão inicial: o Blau Nunes da lenda, mundo da fantasia, é o mesmo narrador dos contos, tão realistas? Luís Augusto Fischer afirma isso ao mesmo tempo em que confere ao autor a invenção singular de atribuir a um personagem que vivenciou $o$ mundo rural que está acabando, a narração sobre esse espaço (FISCHER, 2014, p, 184185). ${ }^{13}$ O Blau dos contos é um crioulo rio-grandense; na lenda, ele se refere a uma avó charrua, é mestiço, portador de tradições indígenas passadas por linha materna. A história se desdobra em três tempos: a chegada dos mouros, ocultos entre os pioneiros da colonização; os acontecimentos na Missão de Santo Tomé Apóstolo, fundada em 1632; e os eventos vividos por Blau na Salamanca que, pelas referências ao cotidiano do campeiro, apontam para os fins do século XIX: ele é posteiro de uma estância e está campeando um boi fugido, mesmo que fosse o Boi Barroso, criatura também fantástica, um animal que aparecia aos campeiro, mas depois nunca era encontrado.

Subindo pelo Cerro do Jarau, Blau se depara com a boca da furna encantada, tão procurada por aqueles atrás de tesouros e outros favores da lendária feiticeira que ali vivia. Nesse lugar, estava "um vulto, de face tristonha e mui branca" (LOPES NETO, 2006, p. 196), o Santão que guardava a salamanca do cerro. Blau saúda-o: "Laus Sus-Cris!" (LOPES NETO, 2006, p. 197), ${ }^{14}$ um cumprimento usual em tempos mais antigos. Na conversa que inicia com o Santão, Blau conta o que já ouviu de sua avó indígena sobre os encantamentos do Jarau.

As histórias contam de mouros perseguidos que vieram fugidos de Salamanca, na Espanha, trazendo um condão mágico cuidado por "uma princesa moça, encantada" (LOPES NETO, 2006, p. 198). A lenda mostra outros tantos marginalizados em terras americanas: heréticos, muçulmanos, falsamente conversos e sua feiticeira: “E de- 
via ter mesmo muita força o condão, porque nem os navios se afundaram, nem os frades de bordo desconfiaram, nem os próprios santos que vinham, não sentiram..." (LOPES NETO, 2006, p. 199). Na América, encontraram outro maldito, Anhangá-Pitã, "diabo-vermelho" da terra, que os acolheu escondendo o condão mágico dos infiéis numa pedra preciosa que serviria de cabeça para a fada, convertida em Teiniaguá, a lagartixa encantada.

Nesse momento, percebem-se novas fronteiras culturais e religiosas: de um lado, os mouros renegados, que se aliaram a Anhangá, entidade guarani ligada à natureza e identificada como o demônio pelos jesuítas; do outro, os cristãos, incluindo os guaranis missioneiros, identificados com Tupã, antigo deus dos trovões, que foi associado a Deus pelos padres inacianos. Anhangá-Pitã, "diabo-vermelho", transformou o poderoso condão "que navegara em navio bento e entre frades rezadores e santos milagrosos" (LOPES NETO, 2006, p. 199) numa pedra também vermelha, talvez um rubi, de muito valor, mas da cor do sangue e dos infernos. O novo aliado se encarregava, então, de esconder os poderes demoníacos dos defensores da Cristandade na América.

Para Mauren Przbylski, a Teiniaguá seria uma representação moura, e este "ser oriental" seria formador dos significados construídos socialmente sobre a Salamanca do Jarau (PRZYBYLSKI, 2009, p. 83). Levanto outra possibilidade: Anhangá seria uma entidade espiritual tupi-guarani ligada à vida animal, não sendo bondosa ou maldosa; sua associação ao Diabo cristão foi feita pelos jesuítas; ${ }^{15}$ também o Yahweh do Gene- sis é o criador, não parecendo ser bom ou mau. Anhangá, depois da criação da Teiniaguá, descansou e descuidou-se dos riscos que trazia sua feminilidade; também no Paraíso, foi a mulher, Eva, quem comeu primeiro da Árvore Proibida. Como é evidente o pouco caso de Simões Lopes em relação aos "padres rezadores", é possível que fosse o próprio culto cristão dos catequistas que estivesse em pauta. O caráter de negatividade ou positividade pode depender de uma visão colonialista que se subverteria numa América mestiça (LOPES, 2012, p. 49).

A Teiniaguá também é portadora de significados diabólicos por ser lagartixa, um réptil como outros seres malignos (CHAVES, 1982, p. 84). Além da serpente bíblica que os padres inculcaram nos missioneiros, os próprios guaranis tinham seus pesadelos com cobras nativas: a venenosa mboicininga, a cobra de chocalho, cascavel; a mboiguaçu, a cobra grande, sucuri; e a mais temida de todas, mboitatá, a cobra de fogo, que aterrorizava os campos atacando os passantes nas noites pampianas. ${ }^{16}$ Nesse sentido, a Teiniaguá poderia ser considerada tão perigosa quanto as serpentes; mesmo não sendo uma ameaça letal quanto aquelas, tinha o mesmo caráter insinuante ou sedutor, mais próximo da cobra edênica que enfeitiçara Adão e Eva, outra referência ao Gênesis!

Ao final do seu relato, Blau retoma outra fronteira marcante para seu tempo/ espaço: os papéis sociais e culturais de homens e mulheres. No mundo masculino que usa da força bruta, as armas femininas são as transgressões. O poder político pertencia aos muçulmanos de Salamanca, mas o feitiço estava com a princesa moura. E Anhangá 
- entidade masculina - ensinou todos os segredos que conhecia à feiticeira que chegara: "Só não tomou tenência que a teiniaguá era mulher..." (LOPES NETO, 2006, p. 200). Ou seja, era uma ameaça para a sociedade dos homens e, mesmo, para um poderoso demônio das terras americanas!

A frase serviu de mote para a história do Santão, iniciada na Missão de Santo Tomé, em cuja igreja ele fora sacristão. Capturando a Teiniaguá - ou sendo capturado por ela! - quando todo o povo dormia, escondeu-a numa guampa e alimentou-a com mel. A guampa dura, símbolo fálico; o mel doce, representação feminina! Nesse momento, já estava a nova "fronteira" da santidade abalada pelo sacristão e pelo pecado que trazia Teiniaguá, feiticeira, princesa e mulher, infiltrada no claustro. E a tentação fatal: "Sou jovem... sou formosa..., e meu corpo é rijo e não tocado!... E estava escrito que tu serias o meu par!" (LOPES NETO, 2006, p. 206).

Para tudo que oferecia, era preciso abandonar a Cristo: "Se a cruz do teu rosário não me esconjurar... Sobre a cabeça da moura amarelejava neste instante o crescente dos infiéis..." (LOPES NETO, 2006, p. 206). E ele pecou mortalmente: “Uma noite ela quis misturar o mel do seu sustento com o vinho do santo sacrifício, e eu fui e busquei no altar o copo de ouro consagrado" que, em seguida, "de boca para boca, por lábios incendiados o passamos..." (LOPES NETO, 2006, p. 207). Descoberto, ele foi condenado ao garrote vil! Mas, salvo na última hora pela Teiniaguá, encontrava-se desde então com ela na Salamanca do Jarau, com todas as riquezas que recolhera, $\mathrm{e}$ "que ficou sendo o paiol de todas as riquezas de todas as salamancas dos outros lugares" (LOPES NETO, 2006, p. 211). O amor da moura salvou o Santão, que o tempo não atingia! O encantamento só findaria quando ele fosse saudado como cristão por três vezes!

Outra fronteira entre o mundo ordenado dos homens e o encantado da furna. Entrar na salamanca dividia o mundo real e lícito daquele que era fantástico e ilícito! “Alma forte e coração sereno!... Quem isto tem, entra na Salamanca, toca o condão mágico e escolhe do quanto quer..." (LOPES NETO, 2006, p. 213). Penetrar no buraco escuro era possuir a Teiniaguá! Bastava vencer as provas da fada moura: liberdade plena ao alcance da transgressão, fortuna dada pelo interdito, pelos feitiços dos infiéis, dos traidores da Igreja e dos demônios ancestrais. Os sortilégios femininos derrubavam todas as muralhas; a Teiniaguá penetrada pelo Santão oferecia as suas dádivas aos corajosos! É uma mulher perdida que comanda as ações da narrativa.

Blau vence as sete provas, mas nega as ofertas da feiticeira! Ele queria mais:

- Teiniaguá encantada! Eu te queria a ti, porque tu és tudo!... És tudo o que eu não sei o que é, porém que atino que existe fora de mim, em volta de mim, superior a mim. $\mathrm{Eu}$ te queria a ti, Teiniaguá encantada!... (LOPES NETO, 2006, p. 219).

Recebe do Santão como consolo uma moeda, uma onça de ouro mágica que jamais se esgotava. O gaúcho despilchado compra arreios, cavalos, gados, terras... Mas o encantamento se torna maldição, ele fica sozinho, isolado pela desconfiança de todos. Assim, procura de novo o Santão, repetindo 
a saudação "Lau Sus Cris!...", joga de volta a onça de ouro: "Devolvo! Prefiro a minha pobreza dantes à riqueza desta onça que nunca se acaba, é verdade, mas que parece amaldiçoada". A terceira saudação, de despedida, "Adeus! Fica-te com Deus, sacristão!", quebra o encanto do cerro, e todas as bruxarias somem numa voragem de fogo.

O casal mágico da Salamanca também muda, revertendo os caminhos trilhados: a feiticeira velha transformou-se na lagartixa; ela, na princesa moura; e finalmente "numa tapuia formosa"; o Santão vira o sacristão missioneiro, e este, um "guasca desempenado" (LOPES NETO, 2006, p. 225). Um par de mortais para gerar um novo mundo? $\mathrm{O}$ fim da salamanca seria também o fim do Rio Grande que Blau conhecera? Talvez nesta narrativa o fantástico represente o real aos tempos do Blau Nunes dos contos, ou Simões Lopes Neto por trás da sua criação.

O guasca pobre conseguiu, na sua simplicidade e desprendimento, terminar com um poderoso feitiço que sobrevivera a Inquisição em Salamanca, escapara à vigilância dos religiosos na viagem para a América e ainda à santidade das missões guaranis. Mas voltava também a pobreza de Blau, pois sua riqueza era indevida; ricos, só os senhores das terras. A sina do gaúcho pobre só pode ser vencida por magias diabólicas, ou ele será sempre um "guasca" que só tem de seu "um cavalo gordo, o facão afiado e as estradas reais" (LOPES NETO, 2006, p. 226). Mais tarde, para os gaúchos, não restaria nem isso!
Saindo da furna...

No Rio Grande do Sul, não são poucos, infelizmente, que alimentam a ideia de um estado branco, trabalhador e ordeiro. Já era assim antes, e a imigração europeia mais recente reiterou essas falas. No entanto, as pesquisas históricas mostram que, no início do século XIX, a província era a terceira na importação de escravos africanos; e outros estudos genéticos provam uma ampla disseminação genética guarani. Há, portanto, um contraponto no passado ainda recente, mestiço e turbulento, ligado às tradições e lidas fronteiriças.

Disso resultou o culto a santos populares, com histórias também fronteiriças: espaciais, textuais e ficcionais! Em outro estudo, tratei do guarani que combateu os exércitos ibéricos, foi santificado, é nome de cidade e tem estátua próxima da antiga redução que defendeu. Há também o negro, ainda guri, nas lidas com os cavalos do senhor, o escravo martirizado no lugar do gaúcho livre...

E, claro, há as "santas prostitutas", uma expressão proposta por Antônio Augusto Fagundes, para mulheres que viviam do meretrício e que foram vítimas de seus amantes ou companheiros, indivíduos pertencentes às polícias locais. Maria Bueno, Maria do Carmo e Maria Degolada; cada Maria transitou do pecado e da promiscuidade sexual para a redenção e a sacralidade (FAGUNDES, 1987). Associação intangível com Maria Madalena... Simões Lopes não dispunha dessas imagens, mas também trouxe uma mulher profana, luxuriosa e pecadora, que alcança a redenção ao final do relato. Ele não traz para cena a mulher pren- 
dada, casta e trabalhadora, a propriamente dita prenda! Traz a Teiniaguá, e basta!

Nessa fronteira entre o real e o fantástico, esfuma-se a outra fantasia travestida de realidade, e o Rio Grande não se revela branco e laborioso. Ele é tributário de um passado indígena de combate pela cruz contra os cristãos, de um passado em que escravos também foram homens que fizeram o pampa a lombo de cavalo, de um passado em que as mulheres estiveram sempre imiscuídas nas relações sociais de lugares onde predominam imagens de virilidade.

A Literatura não traz verdades explícitas; as lendas trazem seus significados nas entrelinhas. Nelas aparecem guaranis traídos, negros torturados, hereges perigosos e mulheres tentadoras. Descendentes deles - e somados a seu mundo -, os gaúchos pobres, mas altaneiros, ocupam os campos! Todos poderiam ameaçar o mundo real, cristão, lusitano, resultado do esforço dos estancieiros ricos, e deveriam ser tirados do espaço produtivo! O que se revela por detrás de todas essas fronteiras - sejam elas espaciais, religiosas, étnicas, culturais ou comportamentais - é talvez aquela mais crua e difícil de cruzar: a de classes sociais, que separa uns e outros irremediavelmente.

A lenda provoca a Literatura, que conversa com a História. Então podemos vislumbrar um pouco do passado rio-grandense.
Abstract

This article aims to study three different types of border, but that can come together in a single direction: 1) one of them identifiable to material and geographical space, but needs the mediation of a historic building; 2) a textual one, which concerns both theoretical developments that reflect the theme, and the fictional production whose objects are the territories and its people; 3 ) and finally, the dimension between the believable and the fantastic, which often can reveal aspects that are difficult to make known empirically.

Keywords: Fiction. Frontiers. History and literature. River Plate. Spatial boundaries.

\section{Resumen}

Este artículo propone el estudio de tres diferentes fronteras, pero que se pueden converger en una sola dirección: 1) una espacial, que solo aparentemente se muestra materialmente identificable, pero que necesita de la mediación de una construcción histórico; 2) una textual, que se refiere tanto a los desarrollos teóricos que reflejan el tema, como a la producción ficcional que tiene como objetivo el territorio y su gente; 3 ) por último, la dimensión entre el verosímil y lo fantástico, que a menudo puede revelar aspectos que difícilmente se dan a conocer empíricamente.

Palabras clave: Ficción. Fronteras. Historia y literatura. Límites espaciales. River de la Plata. 


\section{Notas}

1 Este tema foi desenvolvido parcialmente em texto publicado anteriormente (GUAZZELLI, 2014).

2 Em 2009, publiquei resultados de alguns trabalhos (GUAZZELLI, 2009). Desde 2017, o GT tornou-se nacional, denominado Fronteiras e Territorialidades, com a participação de pesquisadores de vários estados.

3 Também realizei estudos e escrevi sobre as fronteiras na literatura dos Estados Unidos (GUAZZELLI, 2003, p. 124-144; GUAZZELLI, 2009, p. 249-281; 369-384; GUAZZELLI; FREITAS, 2015, p. 209-236).

4 Nas referências, além da obra citada, aponto outras edições de Lendas do Sul (LOPES NETO, 1960, 1988, 2003, 2006, 2011). Também refiro uma tradução para o castelhano do conto em tela, feita por Aldyr García Schlee (LOPES NETO, 1991).

5 No tópico Fatos que realmente aconteceram?, tratarei com mais detalhadamente esta questão.

6 Pequena peça teatral de tom humorístico, muito popular na Espanha.

7 O escritor e diplomata Washington Irving publicou, em 1851, livro sobre sua viagem e estadia na Alhambra, narrando muitos relatos fantásticos (IRVING, 1959).

8 Karl Marx afirmava que Charles Dickens dizia mais sobre o capitalismo do que os economistas ingleses; seu parceiro Friedrich Engels escrevia o mesmo em relação a Balzac e à burguesia; o sociólogo marxista Agustín Cueva afirmava o mesmo sobre o realismo do romance latino-americano.

9 A tradução literal é meias de couro, uma referência às vestimentas de origem indígena.

10 Os livros pela ordem de publicação são: The Pioneer, de 1823 (COOPER, 1964); The Last of the Mohican, de 1826 (COOPER, 1989); The Prairie, de 1827 (COOPER, 1987); The Pathfinder, de 1840 (COOPER, 1980); e The Deerslayer, de 1841 (COPER, 1982).

11 O autor afirma que recolheu os versos de "uma velhíssima mestiça" (LOPES NETO, 2006, p. 235).

12 A importância dada à lenda é evidente mesmo entre destacados historiadores. $\mathrm{O}$ volume 18 dos Anais do Arquivo Histórico do Rio Grande do Sul, dirigido por Luiz Carlos da Cunha Carneiro (2009), contém todos os 80 documentos de Bento Manoel Ribeiro da Coleção Varela (CV-7703 a CV-7782). Entre eles, como em nenhum dos demais 293 documentos que compõem o volume, não há qualquer referência à lenda da salamanca. No entanto, o título do exemplar é Os Segredos do Jarau: documentos históricos sobre a Revolução Farroupilha!
13 Nesse sentido, Simões Lopes Neto seria um precursor de Guimarães Rosa, que usou o mesmo recurso em Grande sertão: veredas. Quanto ao estilo, também vejo muitas semelhanças entre ambos os autores.

14 Corruptela arcaica da expressão: "Louvado Jesus Cristo".

15 Num sincretismo análogo, Tupã, que era uma entidade celestial manifestada pelo trovão, foi ligado ao Deus católico pelos padres.

16 Entre as Lendas do Sul, o autor publicou também A mboitatá (SIMÕES LOPES, 2006, p. 187-192).

\section{Referências}

ABELLA, Gonzalo. Mitos, leyendas y tradiciones de la Banda Oriental. Bloomington (IN): BetumSan Ediciones, 2001. Disponível em: <http:// www.geocities.ws/uruguayoculto/leyendas/ leyendas1.html>. Acesso em: 8 jan. 2018.

ALARCÓN Y MENDOZ, Juan Ruiz. La Cueva de Salamanca. In: Obras Completas: T. I.

Valencia: Albatroz Hiapanofilia, 1990. p. 139171. Disponível em: <www.cervantesvirtual. com>. Acesso em: 10 jan. 2018.

ANDERSON, Benedict. Nação e consciência nacional. São Paulo: Ática, 1989.

ANTUNES, Cláudia Rejane D. A poética do conto de Simões Lopes Neto: o exemplo de "O negro Bonifácio". Porto Alegre: EDIPUCRS, 2003.

ASCASUBI, Hilario. Santos Vega ó los mellizos de la Flor. Buenos Aires: Losada, 1998.

CARNEIRO, Luiz Carlos C. Apresentação. Bento Manoel Ribeiro, o protegido da Teiniaguá. In: ARQUIVO HISTÓRICO DO RIO GRANDE DO SUL (AHRS). Os Segredos do Jarau: documentos sobre a Revolução Farroupilha. Porto Alegre: AHRS/EDIPUCRS, 2009. (Coleção Varela v. 18). p. 9-14.

CERVANTES SAAVEDRA, Miguel de. Entremés de la Cueva de Salamanca. In:

La Cueva de Salamanca en Ocho Comedias y Ocho Entremeses. Madrid: Viuda de Alfonso Martín, 1615. Disponível em: <miguelde.cervantes. $\mathrm{com} / \mathrm{pdf} /$ La cueva de Salamanca.pdf $>$. Acesso em: 17 jan. 2018. 
CHARTIER, Roger. À Beira da Falésia: a história entre incertezas e inquietudes. Porto Alegre: Editora da Universidade, 2002.

COOPER, James Fenimore. The Pioneers. New York: Penguin, 1964.

The Pathfinder (or The Inland Sea). New

York: Penguin Books, 1980.

. The Deerslayer (or The First Warpath). New York: Bantam Books, 1982.

The Prairie. New York: Penguin Books, 1987.

The Last of the Mohicans. New York: Bantam Books, 1989.

CRÓSTA, Alvaro P. et al. Cerro do Jarau, Rio Grande do Sul: a possible new impact structure in southern Brazil. In: GIBSON, Roger L. Large Meteorite Impacts and Planetary Evolution IV. Boulder (CO): Geological Society of America (Special Paper), 2007. p. 173-190. Disponível em: <https:/ / pubs.geoscienceworld.org/books/ book/632/large-meteorite-impacts-and-planetary-evolution-iv>. Acesso em: 12 dez. 2017.

ECHEVERRÍA, Estebán. El Matadero. Buenos Aires: Emecé, 1999.

EAGLETON, Terry. Teoria da Literatura. Uma Introdução. São Paulo: Martins Fontes, 2006.

FAGUNDES, Antônio Augusto. As santas prostitutas: um estudo da devoção popular no Rio Grande do Sul. Porto Alegre: Martins Livreiro, 1987.

FISCHER, Luís Augusto. Simões Lopes Neto e Guimarães Rosa: a literatura e o luto no sertão. Teresa. São Paulo: USP (PPG em Literatura Brasileira), 2014. p. 175-190. n. 14.

FREITAS, Renata Dal Sasso. Páginas do Novo Mundo: um estudo comparativo entre a ficção de José de Alencar e James Fenimore Cooper na formação dos Estados brasileiro e norte-americano no século XIX. 2009. 154 f. Dissertação (Mestrado em História) - Universidade Federal do Rio Grande do Sul, Porto Alegre, 2008.
GRANADA, Daniel. Reseña Histórico-descriptiva de Antiguas y Modernas Supersticiones del Río de la Plata. Buenos Aires: Guillermo Kraft, 1959.

GUAZZELLI, Cesar Augusto B. Matrero, guerreiro, peão campeiro: aspectos da construção literária do gaúcho. In: MARTINS, Maria Helena (Org.). Fronteiras Culturais (Brasil, Uruguai, Argentina). São Paulo: Ateliê, 2002. p. 108-136.

. Fronteiras americanas na primeira metade do século XIX: o triunfo das representações nos Estados Unidos da América. Anos 90, Porto Alegre, n. 18, p. 124-144, dez. 2003.

Fatos que realmente aconteceram? Considerações sobre História e Literatura. In: SILVEIRA, Helder G.; ABREU, Luciano A.; MANSAN, Jaime V. (Org.). História e ideologia: perspectivas e debates. Passo Fundo: UPF Editora, 2009. p. 369-384.

. Servindo à Pátria: Blau, o guasca, da Cisplatina à Guerra do Paraguai. A literatura e a invenção do guerreiro fronteiriço. In: ENCONTRO ESTADUAL DE HISTÓRIA DA ANPUH-RS, 12. Rio Grande (RS). Anais... Rio Grande (RS): ANPUH, 2012. p. 160-167.

. Rio da Prata, século XIX: fronteiras espaciais, textuais e ficcionais. Diálogos. Maringá (PR), v. 18, n. 1, p. 173-206, jan./abr./ 2014.

GUAZZELLI, Cesar Augusto B.; FREITAS, Renata Dal S. Entre cabanas e diligências: os fronteiriços na Western Fiction de Bret Harte e Ernest Haycox. Anos 90, Porto Alegre, v. 22, p. 209-236, 2015.

HALPERÍN DONGHI, Tulio. José Hernández y sus mundos. Buenos Aires: Sudamericana, 1985.

HERCULANO, Alexandre. Lendas e narrativas. Lisboa: Bertrand, 1992.

HERNÁNDEZ, José. Martín Fierro. Buenos Aires: Gador, 2009.

HIDALGO, Bartolomé. Cielitos y Diálogos Patrioticvos. Montevideo: Signo, 1967.

IRVING, Washington. Narrativas da Alhambra. São Paulo: Brasiliense, 1959. 
LOPES NETO, João Simões. Contos gauchescos e Lendas do sul. Introdução, variantes, notas e glossário por Aurélio Buarque de Holanda. Prefácio e nota de Augusto Mayer. Posfácio de Carlos Reverbel. Porto Alegre: Globo, 1960. (Coleção Província, n. 1).

- Contos gauchescos, Lendas do sul e Casos do romualdo. Edição crítica de Ligia Chiappini. Lisboa: Presença, 1988.

- La Salamanca del Jarau. Tradução de Ardyr García Schlee. Porto Alegre: IEL/IGEL, 1991.

. Obras completas. Organização de Paulo Bentancur. Porto Alegre: Sulina, 2003.

. Contos gauchescos e Lendas do sul. Introdução, comentários, notas e glossário de Aldyr Garcia Schlee. Porto Alegre: IEL/Unisinos, 2006. 2 v.

. Contos gauchescos e Lendas do sul. Introdução, fixação de texto e notas de Luís Augusto Fischer. Porto Alegre: L\&PM, 2011.

LOPES, Cícero Galeno. Teiniaguá multifacetada. Nonada Letras em Revista. Porto Alegre, a. 15, v. 2, n. 19, p. 41-48, 2012.

LOPES, Hilda Simões. O cerro do Jarau e as torres de Alhambra. Diário Popular, Pelotas (RS), 29 jun. 2003. Disponível em:

$<$ http:// pelotascultural.blogspot.com. br/2009/10/o-cerro-do-jarau-e-as-torres-de. html>. Acesso em: 10 jan. 2018.

LUSICH, Antonio. Los tres gauchos Orientales y otras poesías. Montevideo: Claudio García, 1937.

MARCOS CELESTINO, Mónica. El Marqués de Villena y la Cueva de Salamanca. Entre Literatura, Historia y Leyenda. Estudios humanísticos. Filología. León, Espanha, n. 26, p. 155-186, 2004. Disponível em: <revpubli.unileon.es/index.php/EEHHFilologia/index>. Acesso em: 17 jan. 2018.

OBLIGADO, Rafael. Santos Vega y otras leyendas argentinas. Buenos Aires: Kapelusz, 1969.
PHILIPP, Ruy Paulo et al. A estrutura de impacto do Cerro do Jarau, Quaraí, RS. Revista Brasileira de Geociências, São Paulo, v. 40, n. 4, p. 468-483, dez. 2010. Disponível em: <ppegeo. igc.usp.br/index.php/rbg/index>. Acesso em: 12 dez. 2017.

PRZYBYLSKI, Mauren Pavão. Representação feminina nos lendários gaúcho e quebequense: os casos de Teiniaguá e Corriveu. 2009. 289 f. Dissertação (Mestrado em Literatura) - Universidade Federal de Santa Catarina, Florianópolis, 2009.

SARMIENTO, Domingo Faustino. Facundo. Civilização e barbárie no pampa argentino. Tradução de Aldyr García Schlee. Porto Alegre: UFRGS, 1996.

SCOTT, Walter. Ivanhoé. Rio de Janeiro: Jackson, 1947. (Coleção Grandes Romances Universais, volume 3 ).

THOMPSON FLORES, Mariana F. da C. Apologia à fronteira (manejada): uma proposta conceitual. In: . Crimes de fronteira: a criminalidade na fronteira meridional do Brasil (1845-1889). Porto Alegre, EDIPUCRS, 2016. p. 47-82.

VARGAS LLOSA, Mário. La verdad de las mentiras. Madrid: Alfaguara, 2002.

VASCONCELOS, Francisco Botelho de M. Historia de las Cuevas de Salamanca. Salamanca, Espanha, 1733. Disponível em: <www.cervantesvirtual.com>. Acesso em: 05 dez. 2017.

VIANA, Javier de. Selección de cuentos. Montevideo: Cruz del Sur, 2006.

VIDAL DE BATTINI, Berta Elena. La Salamanca. In: Cuentos y Leyendas Populares de la Argentina. Buenos Aires: Ministerio de Educación y Justicia, Secretaria de Cultura, Ediciones Culturales Argentinas, 1984. Tomo VIII. p. 263-331.

VIGNOLO, Griselda (Sel.). Cancionero Federal. Buenos Aires: Crisis, 1976. (Cuadernos de Crisis 26). 